\title{
An Intact Kidney Slice Model to Investigate Vasa Recta Properties and Function in situ
}

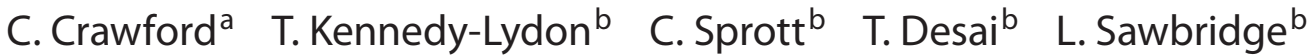 \\ J. Munday ${ }^{b}$ R.J. Unwin ${ }^{c}$ S.S.P. Wildman ${ }^{a} \quad$ C.M. Peppiatt-Wildman ${ }^{a}$
}

${ }^{a}$ Medway School of Pharmacy, The Universities of Kent and Greenwich at Medway, Chatham, b Urinary System Physiology Unit, Royal Veterinary College, and ' UCL Centre for Nephrology, Royal Free Hospital, University College London, London, UK

\section{Key Words}

Kidney $\cdot$ Microvasculature $\cdot$ Medulla $\cdot$ Hemodynamics $\cdot$ Innervation $\cdot$ Tubulovascular crosstalk $\cdot$ Tissue slicing $\cdot$ Live kidney slice model

\begin{abstract}
Background: Medullary blood flow is via vasa recta capillaries, which possess contractile pericytes. In vitro studies using isolated descending vasa recta show that pericytes can constrict/dilate descending vasa recta when vasoactive substances are present. We describe a live kidney slice model in which pericyte-mediated vasa recta constriction/dilation can be visualized in situ. Methods: Confocal microscopy was used to image calcein, propidium iodide and Hoechst labelling in 'live' kidney slices, to determine tubular and vascular cell viability and morphology. DIC video-imaging of live kidney slices was employed to investigate pericyte-mediated real-time changes in vasa recta diameter. Results: Pericytes were identified on vasa recta and their morphology and density were characterized in the medulla. Pericyte-mediated changes in vasa recta diameter (10-30\%) were evoked in response to bath application of vasoactive agents (norepinephrine, endothelin-1, angiotensin-II and prostaglandin $\mathrm{E}_{2}$ ) or by manipulating endogenous vasoactive signalling path-
\end{abstract}

\begin{tabular}{ll}
\hline KARGER & $\begin{array}{l}\text { @ } 2012 \text { S. Karger AG, Basel } \\
\text { 1660-2137/12/1203-0017\$38.00/0 Open access }\end{array}$ \\
$\begin{array}{l}\text { E-Mail karger@karger.ch } \\
\text { www.karger.com/nep }\end{array}$ & $\begin{array}{l}\text { This is an Open Access article licensed under the terms of } \\
\text { the Creative Commons Attribution-NonCommercial 3.0 }\end{array}$ \\
& $\begin{array}{l}\text { License (www.karger.com/OA-license-WT), applicable to } \\
\text { the online version of the article only. Distribution for non- } \\
\text { commercial purposes only. }\end{array}$
\end{tabular}

ways (using tyramine, L-NAME, a cyclo-oxygenase (COX-1) inhibitor indomethacin, and ATP release). Conclusions: The live kidney slice model is a valid complementary technique for investigating vasa recta function in situ and the role of pericytes as regulators of vasa recta diameter. This technique may also be useful in exploring the role of tubulovascular crosstalk in regulation of medullary blood flow.

Copyright $\odot 2012$ S. Karger AG, Basel

\section{Introduction}

Regulation of renal medullary blood flow in physiological and pathophysiological situations is still poorly understood because of the relative inaccessibility of the medullary microcirculation in vivo. In vitro studies using isolated descending vasa recta (DVR) have proposed that several local and systemic factors, such as endothelins (ET), eicosanoids, nitric oxide (NO), angiotensin-II (AngII), adenosine, and ATP, may be involved in its regulation [1]. Regional perfusion studies in which laser Doppler optical fibres have been placed in the renal parenchyma to measure autoregulation of medullary blood flow suggest a link between changes in blood flow, extracellular fluid volume regulation, and salt and water excretion [2-5]. It

Dr. Claire M. Peppiatt-Wildman

Urinary System Physiology Unit

Medway School of Pharmacy, The Universities of Kent and Greenwich at Medway Chatham MEA 4TB (UK)

E-Mail C.M.Peppiatt@kent.ac.uk 
is also thought that the medullary circulation (vasa recta capillaries) is autoregulated (in DVR capillaries over the range of $85-160 \mathrm{~mm} \mathrm{Hg}$ ) and that changes in medullary blood flow are not simply a passive response to changes in renal artery blood flow or pressure; although exactly how this is achieved is still unclear [6]. Furthermore, this subject is not without controversy, the concept of medullary autoregulation has yet to be widely accepted by the field.

Until recently, regulation of tissue blood flow was thought to occur at the level of the arteries and pre-capillary arterioles; however, it has been shown that specialized contractile smooth muscle-like pericyte cells found on capillaries can control capillary diameter in situ in whole retina and in cerebellar brain slices [7]. This is also relevant to the renal medulla, because pericyte cells are present along DVR capillaries [8]. In vitro studies using isolated DVR suggest that the medullary microcirculation is likely to be regulated by locally released vasoactive agents independent of any changes in cortical blood flow [9-14]. Moreover, changes in medullary blood flow are thought to play an important part in the pathogenesis of acute kidney injury [15], and medullary tubulovascular crosstalk could be critical to the control of medullary blood flow in health and disease.

Since the medulla is not readily accessible to direct observation in vivo, except in neonatal rats where the papilla can be exposed by opening the renal pelvis [16], there have been no studies of DVR regulation in the intact medulla, although it is known that pericytes respond to exogenous application of vasoactive agents that can alter isolated DVR diameter [17]. The inaccessibility of the intact medulla means that key endogenous regulators of DVR blood flow have not been investigated in the intact kidney in situ or in vivo. To address this issue, we have developed a 'live' intact kidney slice model to investigate pericyte-mediated regulation of vasa recta diameter in situ in the renal medulla. A potential advantage of the kidney slice model is that although vasa recta are not perfused, the surrounding tubules and local innervation remain intact, and their contributing effects on vasa recta diameter can be explored.

\section{Materials and Methods}

\section{Tissue Slicing}

Animal experiments were conducted in accordance with United Kingdom Home Office Scientific Procedures Act (1986). Adult male Sprague-Dawley rats (250-300 g, purchased from Charles River UK Ltd, Kent, UK) were killed by cervical disloca- tion; their kidneys were immediately removed and placed in icecold physiological saline solution (PSS) bubbled with $95 \% \mathrm{O}_{2} / 5 \%$ $\mathrm{CO}_{2}$ and prepared for slicing. Prior to slicing, the kidneys were de-capsulated and any renal artery remnants removed. A single kidney was secured on the slicing block of a vibratome tissue slicer (Leica model VT1200S; Leica Microsystems (UK) Ltd, Milton Keynes, Bucks., UK), and submerged in a bath of ice-cold PSS bubbled with $95 \% \mathrm{O}_{2} / 5 \% \mathrm{CO}_{2}$. PSS contained (mM) $100 \mathrm{NaCl}$, $5 \mathrm{KCl}, 0.24 \mathrm{NaH}_{2} \mathrm{PO}_{4}, 0.96 \mathrm{Na}_{2} \mathrm{HPO}_{4}, 10 \mathrm{Na}$ acetate, $1 \mathrm{CaCl}_{2}, 1.2$ $\mathrm{MgSO}_{4}, 5$ glucose, $25 \mathrm{NaHCO}_{3}, 5 \mathrm{Na}$ pyruvate (Sigma-Aldrich Ltd, Poole, Dorset, UK). The pH was adjusted to 7.4 using $10 \mathrm{M}$ $\mathrm{NaOH}$. The outer cortical dome region $(\sim 3 \mathrm{~mm}$ tissue) of the kidney was removed to expose the top of the renal medulla and serial $200 \mu \mathrm{m}$-thick coronal kidney slices (in which there was intact cortex and medulla) were cut. Slices were collected and maintained at room temperature in a holding chamber containing PSS, and bubbled with $95 \% \mathrm{O}_{2} / 5 \% \mathrm{CO}_{2}$ to conserve tissue viability. The slices to be used in 'live' experiments were maintained for up to 3 $\mathrm{h}$ in the holding chamber, or slices were fixed with $4 \%$ paraformaldehyde (Sigma-Aldrich Ltd) and used for immunohistochemistry.

\section{Tissue Viability}

To confirm the viability of kidney slices, an on-stage perfusion system was used to load fluorescent dyes into the slices to label all cells (Hoechst 33342) and dead cells (propidium iodide (PI)). Non-fixed kidney slices were secured with a slice anchor in an open-bath chamber $(\sim 1.5 \mathrm{ml}$ volume) (Harvard Apparatus, Edenbridge, Kent, UK) and superfused with PSS bubbled with $95 \% \mathrm{O}_{2} / 5 \% \mathrm{CO}_{2}$ at $5 \mathrm{ml} / \mathrm{min}$. Slices were imaged using a Zeiss 510 NLO Axiovert microscope coupled to a tuneable Coherent Chameleon laser. Prior to imaging of kidney slices, we established the optimum excitation wavelength for each relevant probe imaged using the 2-photon laser, by generating a 2-photon excitation spectrum. Hoechst 33342 (Invitrogen Ltd, Paisley, UK) was used at $5 \mu \mathrm{M}$ to label all cell nuclei and was excited at $720 \mathrm{~nm}$. PI (Sigma-Aldrich Ltd) is taken up by cells with compromised cell membranes and was used at $20 \mu \mathrm{M}$ to label the nuclei of all dead cells and was excited at $543 \mathrm{~nm}$ with a single photon laser. Emitted light was collected with the following filters: band-pass $435-485 \mathrm{~nm}$ (Hoechst 33342) or long-pass $560 \mathrm{~nm}$ (PI). Image processing was performed using Zeiss LSM image browser software (Carl Zeiss Ltd, Welwyn Garden City, Herts., UK). The ratio of live:dead cells (Hoechst labelled:Hoechst-PI co-labelled, respectively) was also calculated using Zeiss LSM image browser software.

To further validate cell viability, and to distinguish between tubular and vascular cells, live kidney slices were incubated for 20 min with the cell-permeant calcein-AM dye. This non-fluorescent dye is converted to a bright green fluorescence by intracellular esterases following uptake into live cells [18]. Calcein-AM (Invitrogen Ltd) was used at $2 \mu \mathrm{M}$ (in $0.002 \%$ pluronic acid) as a vital stain and excited at $800 \mathrm{~nm}$; emitted light was collected using band-pass 500-550 $\mathrm{nm}$. Image processing was performed using Zeiss LSM image browser software, as before.

\section{Immunohistochemistry}

Live kidney slices were incubated with Alexa Fluor 488-conjugated isolectin $\mathrm{B}_{4}\left(\mathrm{IB}_{4}\right)$ (Invitrogen Ltd) - a marker for $\alpha$-D-galactosyl residues - to identify the vasa recta capillaries. $\mathrm{IB}_{4}(50 \mu \mathrm{g} / \mathrm{ml})$ was prepared in PSS bubbled with $95 \% \mathrm{O}_{2} / 5 \% \mathrm{CO}_{2}$; slices were in- 
cubated with $\mathrm{IB}_{4}$ for 45 min, washed with PSS and subsequently fixed using $4 \%$ paraformaldehyde. Fixed kidney slices were then incubated for $16 \mathrm{~h}$ with the anti-neural-glial 2 (NG2) polyclonal antibody (Millipore UK Ltd, Watford, UK). The anti-NG2 antibody, previously used to identify pericytes in the CNS [7], was probed with an Alexa Fluor 555-conjugated donkey anti-rabbit secondary antibody (Invitrogen Ltd). For experiments in which pericytes were co-localized with sympathetic nerves, slices were incubated with anti-NG2 and anti-tyrosine hydroxylase (Vector Laboratories Ltd, Peterborough, UK) primary antibodies, respectively. The tyrosine-hydroxylase signal was amplified with a biotinylated secondary antibody and probed with a FITC-conjugated tertiary antibody (Fluorescent Avidin Kit; Vector Laboratories Ltd). Kidney slices were mounted using Citiflour (Agar Scientific Ltd, Stanstead, Essex, UK) and the medulla of fixed slices were imaged using a Zeiss LSM 510 laser scanning confocal microscope (Carl Zeiss Ltd). Alexa 488-conjugated $\mathrm{IB}_{4}$ and FITC-conjugated secondary antibodies were excited at $488 \mathrm{~nm}$ and Alexa Fluor 555-conjugated secondary antibody excited at $543 \mathrm{~nm}$. Emitted light was collected with the following filters: long-pass $560 \mathrm{~nm}$ (Alexa Fluor 555) and band-pass 505-550 $\mathrm{nm}$ (FITC and $\mathrm{IB}_{4}$ ). Pericytes on the vasa recta were imaged in both the inner and outer medulla.

Confocal images of fluorescently labelled pericytes (Alexa 555, red) and vasa recta capillaries (Alexa 488, green) were used to: (i) calculate the density of pericytes in both the inner and outer medulla, (ii) to measure the average primary $1^{\circ}$ process length [19] and cell body length of pericytes in both regions. For density calculations, $\geq 3 \times 100-\mu \mathrm{m}^{2}$ regions in both the inner and outer medulla of every kidney slice were selected at random $(n=20$ for inner and outer medulla). Measurements of pericyte cell body length and $1^{\circ}$ process lengths in both the outer and inner medulla were measured using Zeiss LSM image browser software.

\section{Functional Experiments and Analysis}

Live kidney slices were secured in an open-bath chamber using a purpose-built platinum slice anchor and transferred to the stage of an upright Olympus microscope (model BX51WI; Olympus Microscopy, Southend-on-Sea, Essex, UK). Kidney slices were continuously superfused $(\sim 2.5 \mathrm{ml} / \mathrm{min}, 1.25 \mathrm{ml}$ bath volume) with PSS, bubbled with $95 \% \mathrm{O}_{2} / 5 \% \mathrm{CO}_{2}$ and maintained at room temperature. Pericytes on the vasa recta capillaries (vasa recta were defined as $<10 \mu \mathrm{m}$ in diameter) were identified by their previously established 'bump-on-a-log' morphology [7], and DIC images were captured through an Olympus $60 \times$ water immersion objective ( $0.9 \mathrm{NA})$. Real-time video images of changes in vasa recta diameter were collected every second by an attached Rolera XR CCD camera and recorded using Image Pro Software (Media Cybernetics Inc., Marlow, Bucks., UK). Live kidney slices were superfused with the following vasoactive compounds: Ang-II (10 and $100 \mathrm{nM}$; see online supplementary video 1, www. karger.com/doi/10.1159/000339110), norepinephrine (NE; $10 \mathrm{nM}$ ), endothelin-1 (ET-1; $10 \mathrm{nM})$, indomethacin $(30 \mu \mathrm{M})$, and $\mathrm{L}_{-} \mathrm{N}^{\mathrm{G}}$-nitroarginine methyl ester (L-NAME; $1 \mathrm{mM}$ ), to evoke vasoconstriction, and the NO donor, S-nitroso-N-acetyl-D,L-penicillamine (SNAP; $100 \mu \mathrm{M})$ and prostaglandin $\mathrm{E}_{2}\left(\mathrm{PGE}_{2} ; 10 \mu \mathrm{M}\right)$ were used to evoke vasodilation. All vasoactive compounds were purchased from Sigma-Aldrich Ltd), and working solutions were prepared in oxygenated PSS. In experiments in which ATP release (from tubules) was stimulated, a hypotonic PSS solution ( $\mathrm{NaCl}$ concentration reduced by $5 \%$ ) was applied to live kidney slices.

Kidney Slice Model to Study Vasa Recta

Pericyte Function
Time-series analysis of live kidney slice experiments was carried out using the public domain software ImageJ (NIH, http:// rsb.info.nih.gov.ij). For each experiment, both a pericyte site and a non-pericyte site were identified on a single vasa recta. The diameter of the vasa recta at both locations was measured every 5 frames for the duration of the experiment (1 frame $=1 \mathrm{~s}$ ). Typically, kidney slices were superfused with PSS alone for 70 s to establish a baseline vessel diameter at the pericyte and non-pericyte site. Slices were then exposed to an agonist/antagonist to evoke a change in vasa recta diameter, and were then subjected to a PSS wash (see online suppl. video 1). Each capillary acted as its own control; an average of the first 5 measurements was taken to represent the resting baseline diameter value $\left(D_{b}\right)$, and expressed as $100 \%$, for both pericyte and non-pericyte sites. All subsequent diameter measurements (D) were calculated and expressed as a percentage of the corresponding baseline value for both pericyte and non-pericyte sites (see equations 1 and 2). Percentage change in vessel diameter was calculated from actual vessel diameter measurements made throughout each experiment; the smaller changes in a vessel diameter reported here (e.g. $2 \%$ of $9.5 \mu \mathrm{m}$ vessel) are calculated rather than measured changes. In our experiments, we calculate that $10 \mu \mathrm{m}$ is defined by 47 pixels, which is measurable.

$$
\% \Delta \text { vessel diameter }=\left(\frac{\text { measured diameter }(D)}{\text { mean baseline diameter }\left(D_{b}\right)}\right) \times 100
$$

$\%$ constriction or dilation $=$

$$
100 \% \text { (baseline) }-\% \Delta \text { vessel diameter }
$$

For all experiments, statistical significance was calculated using Student's t test; $\mathrm{p}<0.05$ was considered significant. Values are expressed as mean $\pm \mathrm{SE}$. $\mathrm{N}$ numbers displayed represent number of pericytes (1 pericyte and non-pericyte site per kidney slice), since the variation observed, and found in similar kidney [20] and CNS studies [7], occurred between pericytes and not animals. All experiments were performed in at least 3 different animals. One vasa recta per kidney slice was used to ensure all vessels were 'naive' prior to exposure to any drug.

\section{Results}

\section{Viability of Kidney Tissue Slices}

A selection of fluophores was used to assess the viability of the live kidney tissue slices. Figure la shows a typical live kidney slice loaded with Hoechst (fig. 1ai) and PI (fig. 1aii), an overlay of Hoechst and PI (fig. 1aiii), a brightfield DIC image of the corresponding area (fig. 1aiv), and an overlay of all images (fig. lav). In three independent experiments we determined the ratio of Hoechst:Hoechst and PI (live:dead) labelled nuclei to be 5:1 (per $100 \mu \mathrm{m}^{2}$, $\mathrm{n}=5$ slices, $\mathrm{n}=3$ animals), indicating that the majority of tubular and vascular cells within the kidney slice were live, thus confirming the tissue slices were viable (fig. 1aiii). Tubules and vasa recta capillaries loaded with 

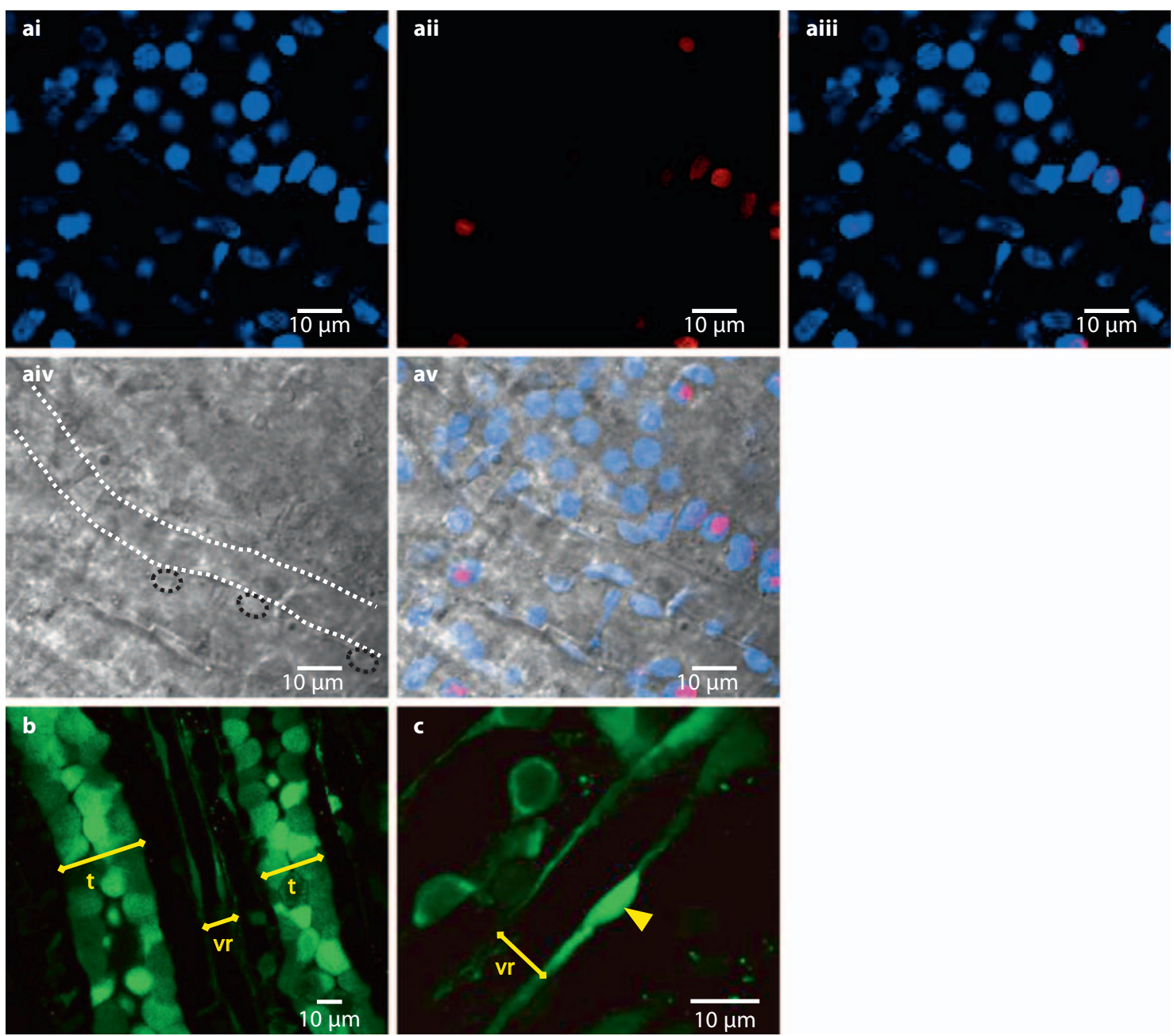

Fig. 1. Viability of kidney slices. Confocal images of kidney slices incubated with Hoechst and PI to label nuclei of all (ai) and dead (aii) cells, respectively. Overlay of images ai and aii demonstrates the ratio of live:dead cells (aiii). The corresponding brightfield image indicates the location of pericytes (aiv, black dotted lines) on a single vasa recta capillary (aiv, white dotted lines). Overlay of images ai-aiv shows all pericytes in this field of view are live (av). Calcein uptake is shown in tubules $(\mathrm{t})$ and vasa recta capillaries (vr) in the renal medulla of live kidney slices (b). Pericytes (arrowhead) were also labelled by calcein (c). the viable marker calcein and were clearly fluorescent, and therefore considered viable $(\mathrm{n}=9$ slices, $\mathrm{n}=3$ animals; fig. 1b). In addition, it was observed that capillaries and vessels consistently run in parallel in the renal medulla. Tubules of different sizes were observed, ranging from 10 to $40 \mu \mathrm{m}$ in diameter ( $\mathrm{n}=9$ slices, $\mathrm{n}=3$ animals). The average diameter of vasa recta capillaries was $7.9 \pm$ $0.6 \mu \mathrm{m}$ ( $\mathrm{n}=9$ slices, $\mathrm{n}=3$ animals). Pericytes were identified on the outside of capillaries by their previously defined 'bump-on-a-log' morphology [7] and they were also fluorescent, indicating that pericytes in our live kidney slices were also viable (fig. 1c, arrowhead).

\section{Characteristics of Vasa Recta Pericytes in situ}

Vasa recta and pericytes were labelled with fluorescently conjugated $\mathrm{IB}_{4}$ (fig. 2ai) and with anti-NG2 (fig. 2aii), respectively. Confocal images of labelled kidney slices were used to identify the prominent pericytes cell body (bump-on-a-log) and processes that run along and wrap around the abluminal surface of vasa recta capillaries (fig. 2aiii). Pericytes were observed at regular intervals along the vasa recta in both the inner and outer medulla. $1^{\circ}$ processes were seen to extend from the pericyte cell body along and around the vasa recta (fig. 2aiii), as previously described in electron microscopy studies 

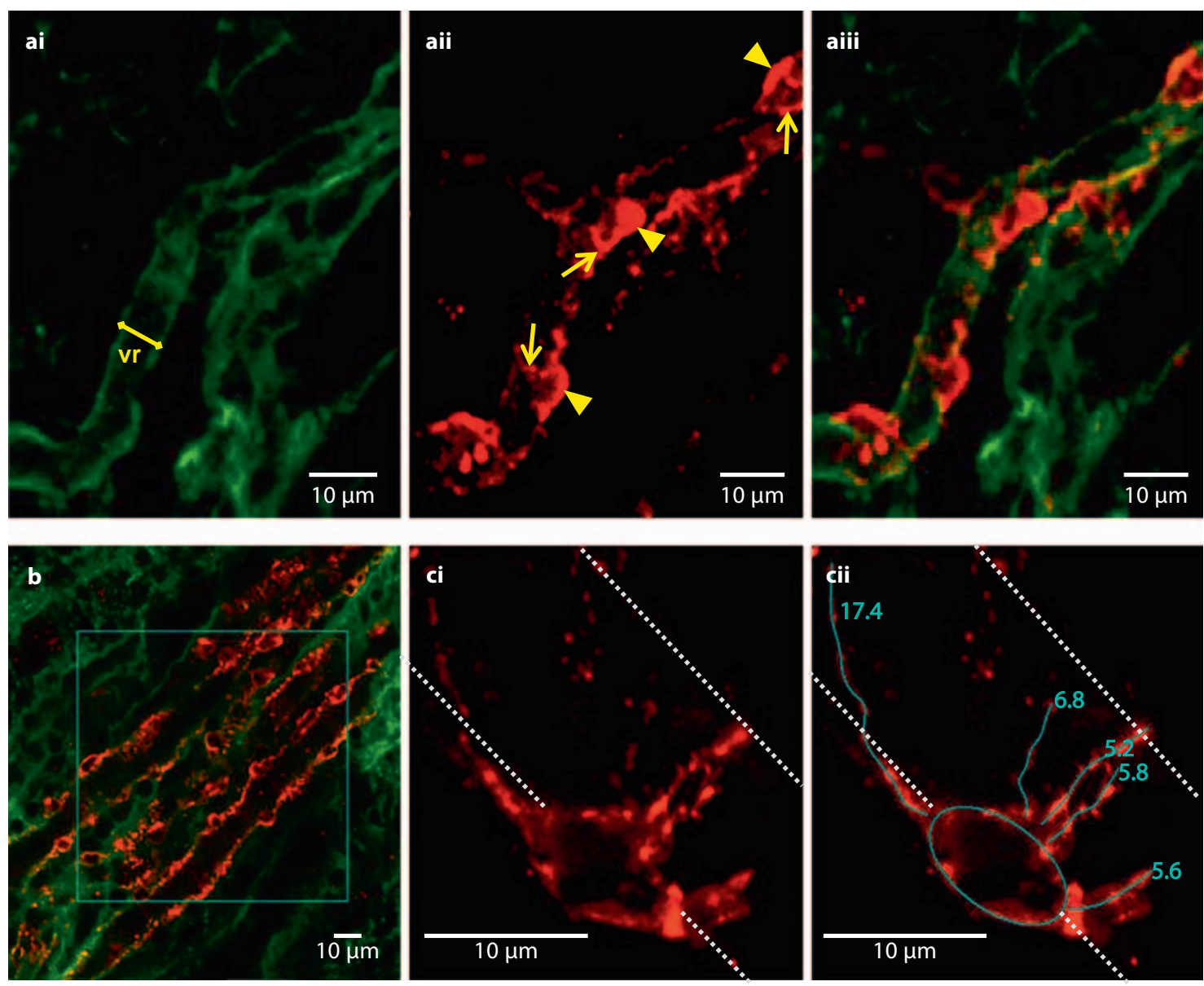

Fig. 2. Identification and characterization of pericytes on vasa recta capillaries in the renal medulla. Vasa recta capillaries (vr) were labelled with Alexa-488-conjugated $\mathrm{IB}_{4}(\mathbf{a i}$, green). The cell body (arrowheads) and processes (arrows) of pericytes in the renal medulla were labelled with anti-NG2 and Alexa-555-conjugated secondary antibody (aii, red). An overlay of images ai and aii identifies pericytes (red) on vasa recta capillaries (green) (aiii). The density of pericytes was calculated for both inner and outer medulla, by selecting $100-\mu \mathrm{m}^{2}$ regions in confocal images of NG2 and $\mathrm{IB}_{4}$-labelled kidney slices (b). A magnified image of a pericyte (ci) shows the cell body and processes (dotted lines indicate outer vessel wall). Cell body length and $1^{\circ}$ processes (running along and around the vessel) were measured (cii, vessel outline indicated by dotted lines).
[19]. $\mathrm{IB}_{4}$ labelling did not distinguish between descending (DVR) and ascending (AVR) limbs.

Wide-field images of vasa recta and pericytes were collected from 3 animals, 3 tissue slices per animal, and pericyte characteristics were determined by analysing $100 \mu \mathrm{m}^{2}$ areas in both inner and outer medulla regions per kidney slice (fig $2 \mathrm{~b}$ ). The pericyte density per 100 $\mu \mathrm{m}^{2}$ in the outer medulla was significantly greater than that in the inner medulla $\left(\mathrm{n}=20,100 \mu \mathrm{m}^{2}\right.$ regions analysed for each region, $\mathrm{p}<0.05$; table 1 ). There was no significant difference in pericyte cell body or process length between the inner and outer medulla; the mean pericyte cell body length was $9 \mu \mathrm{m}(\mathrm{n}=99)$ and mean pericyte process length was $9 \mu \mathrm{m}(\mathrm{n}=158$; table 1$)$. The mean distance between pericyte cell bodies was $16 \mu \mathrm{m}(\mathrm{n}=91)$. Interestingly, process length ranged from 2 to $18 \mu \mathrm{m}$, with $1^{\circ}$ processes running along the vasa recta and wrapping around the vessel (fig. 2ci, ii).

Sympathetic nerve varicosities in the medulla were labelled with an anti-tyrosine hydroxylase antibody and were found to run along vasa recta in close proximity to both inner and outer medullary pericytes (fig. 3). Staining for sympathetic nerves was predominantly detected in the outer medulla, in keeping with the higher density of pericytes found in this area of the medulla. 
Fig. 3. Co-localization of pericytes and sympathetic nerves in the renal medulla. Confocal image of vasa recta pericytes labelled with anti-NG2 and Alexa-555-conjugated secondary antibody (a, red). Sympathetic nerve varicosities were identified with FITC-labelled anti-tyrosine hydroxylase (b, green). An overlay of images $\mathbf{a}$ and b shows pericytes (red) co-localized with sympathetic nerves (green) on a vasa recta capillary (c).
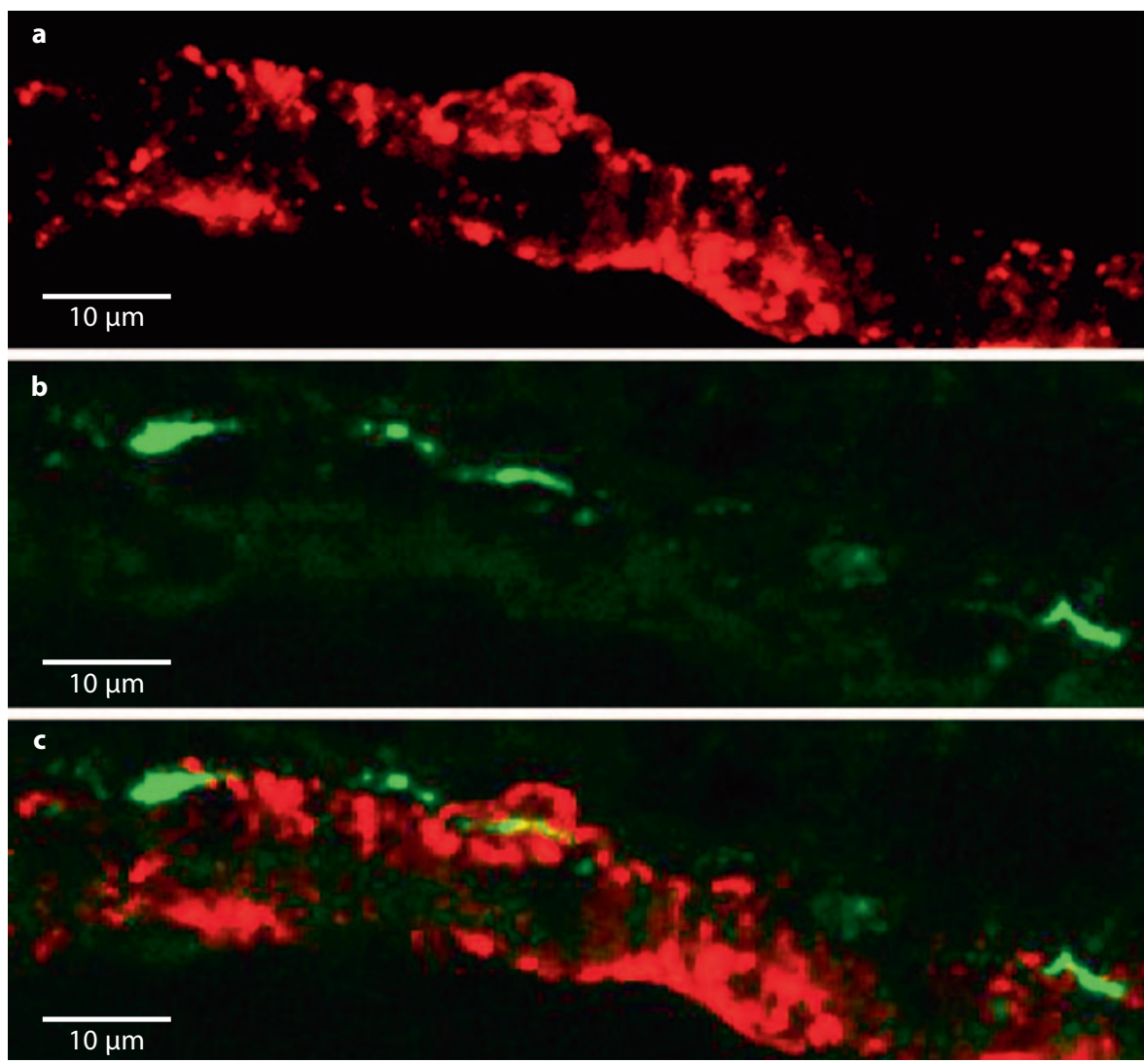

Table 1. Characterization of pericytes in the renal medulla

\begin{tabular}{lrrr}
\hline & \multicolumn{1}{l}{$\begin{array}{l}\text { Inner } \\
\text { medulla }\end{array}$} & $\begin{array}{l}\text { Outer } \\
\text { medulla }\end{array}$ & \multicolumn{1}{c}{$\begin{array}{l}\text { Com- } \\
\text { bined }\end{array}$} \\
\hline Pericyte density (per $\left.100 \mu \mathrm{m}^{2}\right)$ & $9.1 \pm 0.5^{*}$ & $12.4 \pm 1.2$ & $10.8 \pm 0.7$ \\
Pericyte cell-body length, $\mu \mathrm{m}$ & $8.9 \pm 0.2$ & $9.1 \pm 0.2$ & $9.0 \pm 0.2$ \\
Distance between pericytes, $\mu \mathrm{m}$ & $16.0 \pm 1.2$ & $15.1 \pm 1.1$ & $15.6 \pm 1.8$ \\
$1^{\circ}$ process length, $\mu \mathrm{m}$ & & & \\
$\quad$ Along vessel & $7.9 \pm 0.5$ & $8.9 \pm 0.6$ & $8.3 \pm 0.4$ \\
$\quad$ Around vessel & $0.3 \pm 0.6$ & $8.6 \pm 0.5$ & $9.0 \pm 0.4$ \\
$\quad$ Combined & $8.6 \pm 0.4$ & $8.7 \pm 1.1$ & $8.7 \pm 0.3$ \\
\hline
\end{tabular}

Pericyte density, cell-body length, distance between pericytes, and $1^{\circ}$ process lengths of the inner and outer medulla were calculated from confocal images of NG2-stained kidney slices $(n=3$ slices per animal, $\mathrm{n}=3$ animals). Pericyte density was calculated from $100-\mu \mathrm{m}^{2}$ regions in the inner and outer medulla. Values are mean \pm SE. ${ }^{*} \mathrm{p}<0.05$ inner vs. outer medulla.

\section{Effect of Vasoactive Agents on Vasa Recta Diameter in situ}

The initial resting internal diameter of vasa recta capillaries was $7.5 \pm 0.4 \mu \mathrm{m}$ at pericyte sites, significantly narrower than at non-pericyte sites $(9.5 \pm 0.4 \mu \mathrm{m}, \mathrm{n}$ $>30, p<0.001)$. Several vasoactive compounds were tested for their ability to alter vasa recta diameter at pericyte and non-pericyte sites. Changes in vessel diameter were determined by measuring the diameter of the capillary at pericyte and non-pericyte sites before, during, and after the application of a vasoactive compound (see Methods, and figure 4ai-iii and online suppl. video 1 for example of Ang-II-evoked constriction). A representative trace showing the Ang-II (100 nM)-evoked change in vessel diameter at a pericyte and corresponding non-pericyte site is displayed in figure $4 \mathrm{~b}$. We calculated that, on average, $51 \%$ of pericytes responded to agonist exposure by changing vessel diameter. The success rate ranged from 35 to $85 \%$ depending on the agonist vessels were exposed to. Ang-II (100 nM) caused a significantly greater vasoconstriction $(\sim 4$-fold $)$ at pericyte sites $(29.3 \pm$ 
Fig. 4. DIC imaging of pericyte-mediated constriction of in situ vasa recta capillaries. Images taken from a time series experiment in which kidney slices were exposed to Ang-II. A typical field of view of a vasa recta capillary superfused with control PSS solution is shown (ai). Red blood cells are seen in the lumen and pericytes located on capillary walls (ai, arrowhead). Red and yellow dotted lines highlight the regions along the vasa recta where the vessel diameter was measured at pericyte sites and non-pericyte sites, respectively (ai-iii). Application of Ang-II (100 nM) caused a reduction in vasa recta diameter at the pericyte site (aii). Following removal of Ang-II from the perfusate, the vasa recta returned to resting diameter (aiii). A representative trace (b) of \% change in vasa recta diameter at a pericyte site (red trace), and non-pericyte site (grey trace), in response to Ang-II (100 nM) exposure. Mean data for these experiments shows Ang-II (100 nM) evoked a significantly greater vasoconstriction at pericyte sites (black bar) compared with non-pericyte sites (grey bar); ${ }^{*} \mathrm{p}<0.05(\mathbf{c})$.

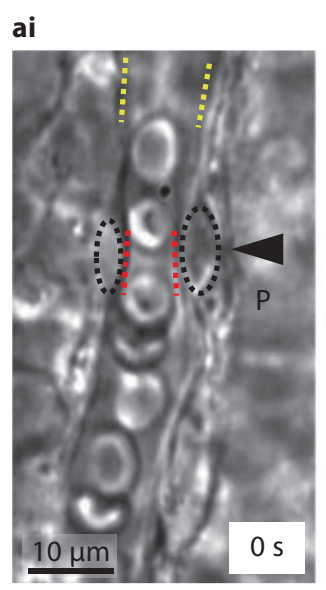

PSS aii

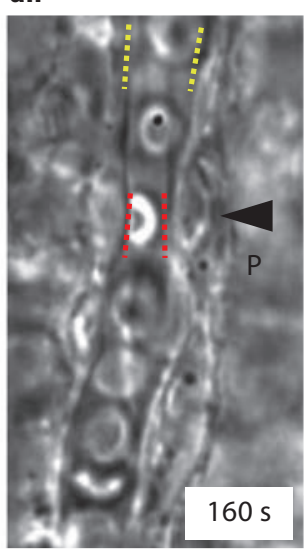

Ang-II

$(100 \mathrm{~nm})$ aiii

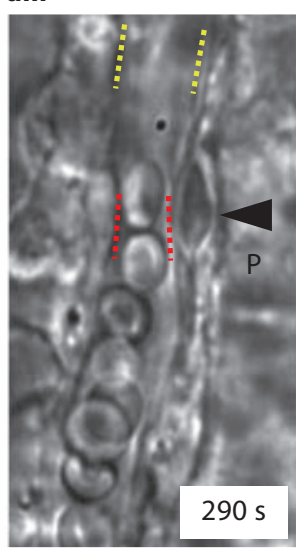

PSS

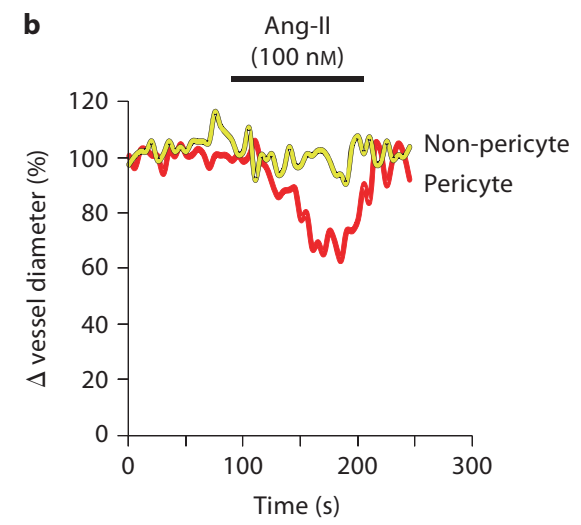

c

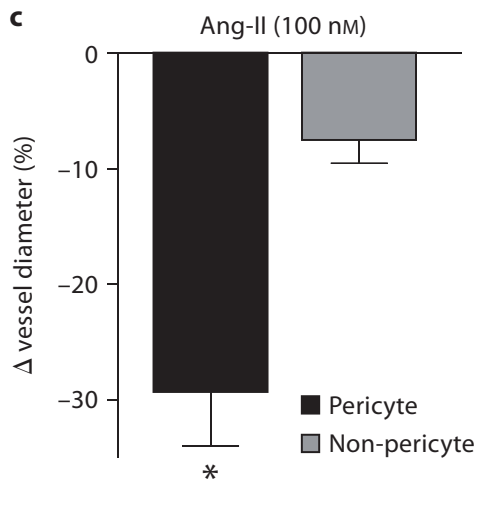

4.7\%) than at non-pericyte sites $(7.6 \pm 1.9 \%, \mathrm{n}=14$ slices, $\mathrm{n}=6$ animals, $\mathrm{p}<0.001$; fig. $4 \mathrm{c}$, online suppl. video 1). Similarly, NE (10 nM) significantly decreased vasa recta diameter by $20.8 \pm 5.1 \%$ at pericyte sites compared with $7.6 \pm 2.0 \%$ at non-pericyte sites $(\mathrm{p}<0.05, \mathrm{n}=7$ slices, $\mathrm{n}=3$ animals; fig. 5ai); ET-1 (10 $\mathrm{nM})$ also caused significant vasoconstriction at pericyte sites $(10.3 \pm$ $1.9 \%)$ compared with non-pericyte sites $(2.4 \pm 1.7 \%, \mathrm{n}=$ 6 slices, $\mathrm{n}=3$ animals, $\mathrm{p}<0.05$; fig. 5bi). Using Poiseuille's law, which assumes laminar flow, as an approximation [21], and not allowing for the presence of red blood cells [22], the constriction evoked by NE (21\%), Ang-II (29\%) and ET-1 (10\%) would increase resistance to blood flow by 2.7-, 4- and 1.5-fold, respectively. The application of the NO donor SNAP $(100 \mu \mathrm{M})$ caused a modest but significantly greater dilation of vasa recta at pericyte sites $(12.6 \pm 2.9 \%)$ compared with non-pericyte sites $(3.7 \pm 1.3 \%, \mathrm{n}=15$ slices, $\mathrm{n}=8$ animals, $\mathrm{p}<0.01$; fig. 5ci). Representative images of NE, ET-1 and SNAPevoked changes in vessel diameter at pericytes are shown in figure 5aii-iv, bii-iv and cii-iv, respectively.

In further experiments, the Ang-II (10 nM)-evoked and ET-1 (10 nM)-evoked constrictions of vasa recta at pericyte sites was attenuated by the NO donor SNAP (100 $\mu \mathrm{M}$; fig. 6). Ang-II (10 nM) and ET-1 (10 nM) evoked an $18.0 \pm 2.7 \%(\mathrm{n}=4$ slices, $\mathrm{n}=3$ animals $)$ and $8.5 \pm 1.9 \%$ ( $\mathrm{n}=10$ slices, $\mathrm{n}=3$ animals) constriction at pericyte sites, respectively, which was significantly greater than that measured at non-pericyte sites $(2.8 \pm 0.7 \%, \mathrm{p}<0.01, \mathrm{n}=$ 4 slices, $\mathrm{n}=3$ animals, and $4.7 \pm 1.4 \%, \mathrm{p}<0.05, \mathrm{n}=10$ slices, $\mathrm{n}=3$ animals, respectively). SNAP $(100 \mu \mathrm{M})$ reduced the Ang-II (10 nM)-evoked constriction by $67.7 \%$ (to $5.8 \pm 1.6 \%$ ) at pericyte sites (fig. 6), and the ET-1 (10 nM)-evoked constriction by $145.9 \%$ thus causing vasa recta to dilate to $+3.9 \pm 1.9 \%$ of the original resting diameter at pericyte sites. Removal of Ang-II (10 nM) from 

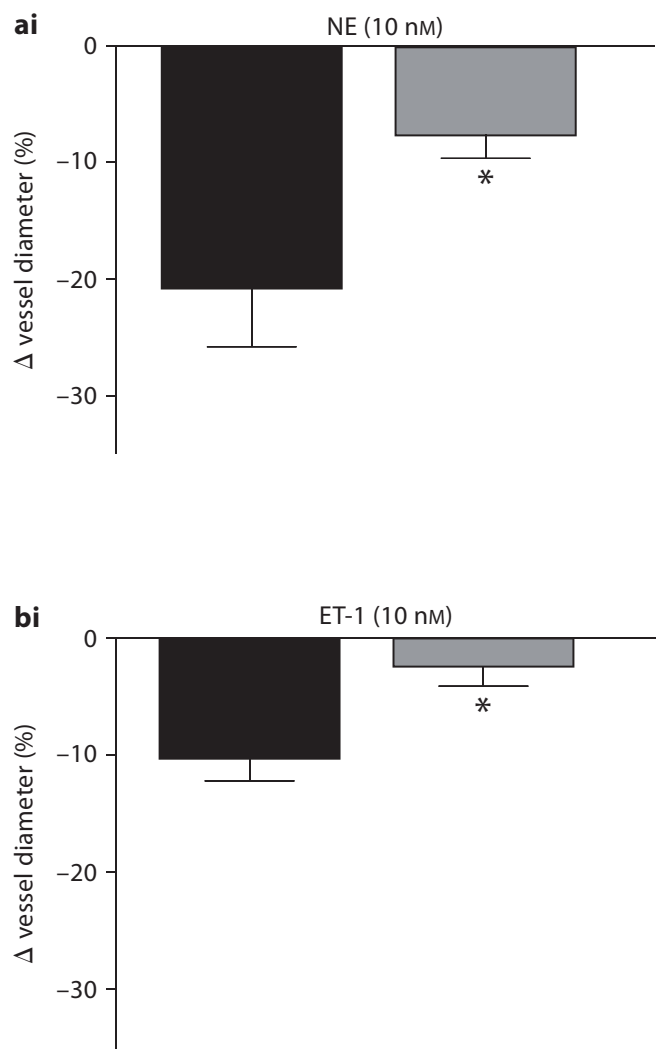

ci

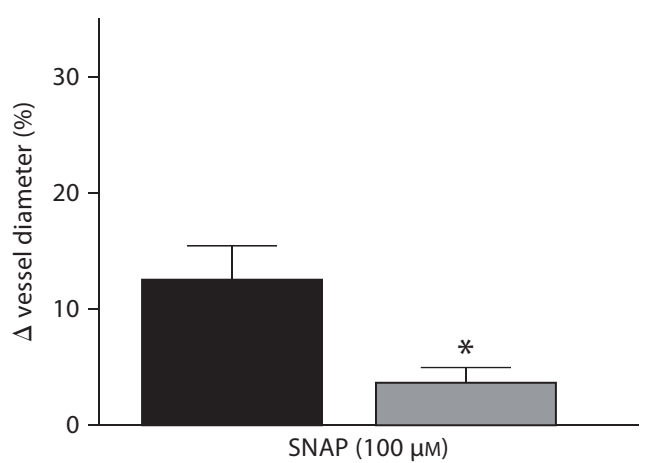

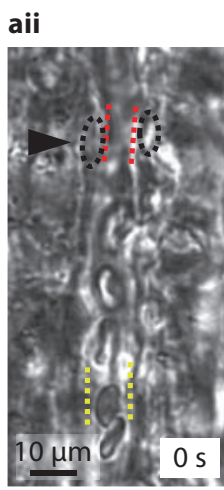

PSS

bii

aiii

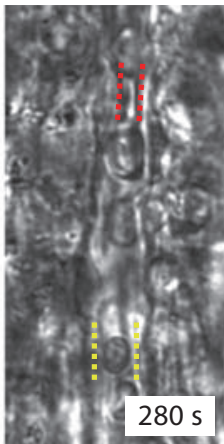

$\mathrm{NE}$

$(10 \mathrm{nM})$

biii

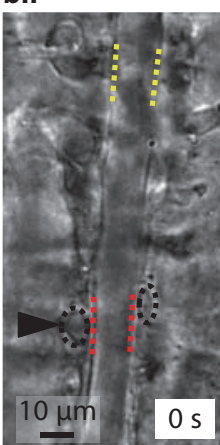

PSS

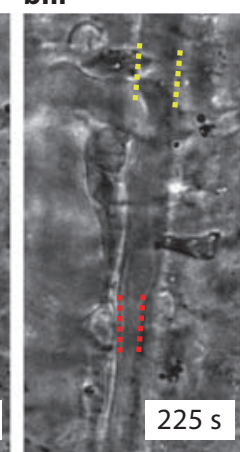

biv

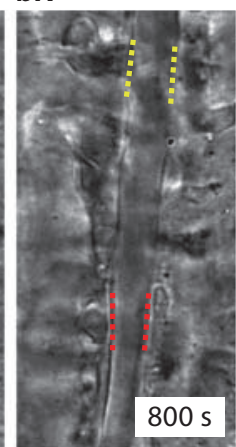

$\mathrm{ET}-1$

$(10 \mathrm{nM})$

cii

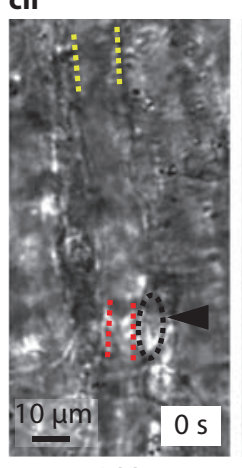

PSS

ciii

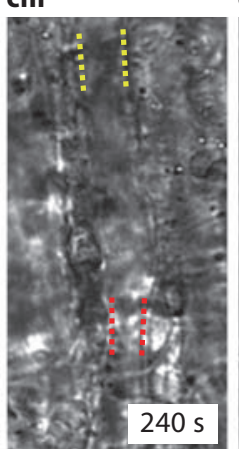

civ

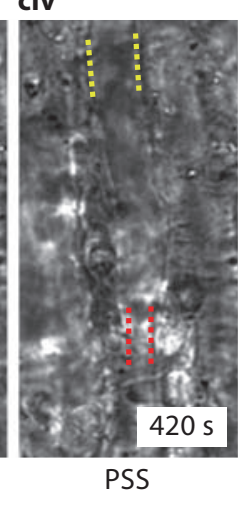

Fig. 5. Effect of vasoactive compounds on vasa recta diameter. Superfusion of live kidney slices with NE (10 nM), and ET-1 (10 $\mathrm{nM}$ ) evoked a significantly greater constriction of vasa recta at pericyte sites (black bars) than non-pericyte sites (grey bars), ai and bi, respectively. The NO donor, SNAP $(100 \mu \mathrm{M})$ evoked a significantly greater dilation of vasa recta at pericyte sites compared with non-pericyte sites (ci). Values are mean $\pm \mathrm{SE},{ }^{*} \mathrm{p}<0.05$.
Representative images of a pericyte site and non-pericyte site predrug exposure (i), during superfusion of the drug (ii), and during washout of the drug (iii), are shown for experiments a-c. Pericytes are denoted by black dotted circles, red dotted lines indicate where maximal constriction/dilation occurs at pericyte sites, and yellow dotted lines indicate the corresponding non-pericyte region of the same vasa recta. 


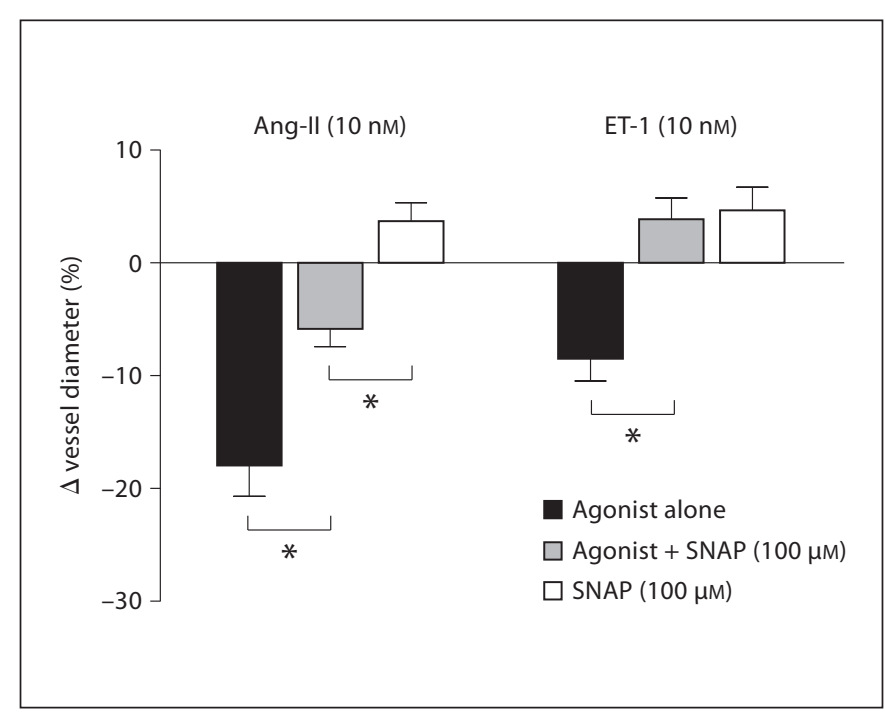

Fig. 6. Co-application of SNAP with agonist (Ang-II or ET-1) attenuated the agonist-evoked constriction of vasa recta at pericyte sites. Co-application of SNAP (100 nM) with either Ang-II (10 nM) or ET-1 (10 nM) significantly decreased both the Ang-II- and ET1 -evoked constriction at pericyte sites, by $70 \%(n=4)$ and $150 \%$ $(\mathrm{n}=10)$, respectively. Removal of Ang-II (10 nM) from the perfusate caused a further dilation of vasa recta at pericyte sites beyond resting diameter, removal of ET-1 (10 $\mathrm{nM})$ did not result in any greater dilation. No significant change in the vessel diameter was measured at non-pericyte sites throughout the experiment. Values are mean \pm SE. ${ }^{*} \mathrm{p}<0.05$.

the perfusate caused a further dilation by SNAP to +3.7 $\pm 1.6 \%$ of the original resting diameter at pericyte sites $(\mathrm{p}<0.05, \mathrm{n}=4$ slices, $\mathrm{n}=3$ animals; fig. 6 ), whereas removal of ET-1 from the perfusate, leaving SNAP alone, failed to evoke a further significant dilation at either pericyte or non-pericyte sites. SNAP also failed to attenuate the Ang-II-evoked constriction of vasa recta at pericyte sites when higher concentrations of Ang-II (100 nM) were used (data not shown). No significant changes in vasa recta diameter were observed at non-pericyte sites during these experiments (data not shown).

Co-application of the $\mathrm{AT}_{1}$ receptor antagonist losartan (10 nM) with Ang-II (100 nM) significantly and reversibly attenuated the Ang-II (100 nM)-evoked vasoconstriction of vasa recta at pericyte sites $(15.3 \pm 1.9 \%)$ by $\sim 30 \%$ to $10.9 \pm 2.2 \%(\mathrm{p}<0.05, \mathrm{n}=8$ slices, $\mathrm{n}=3$ animals; fig. 7$)$. Higher concentrations of losartan (100 nM) irreversibly abolished the Ang-II-evoked vasoconstriction of vasa recta at pericyte sites ( $\mathrm{n}=9$ slices, $\mathrm{n}=3$ animals; fig. 7 ). Superfusion of live kidney slices with the $\mathrm{AT}_{1}$ receptor antagonist losartan alone, at both 10 and $100 \mathrm{~nm}$ had no

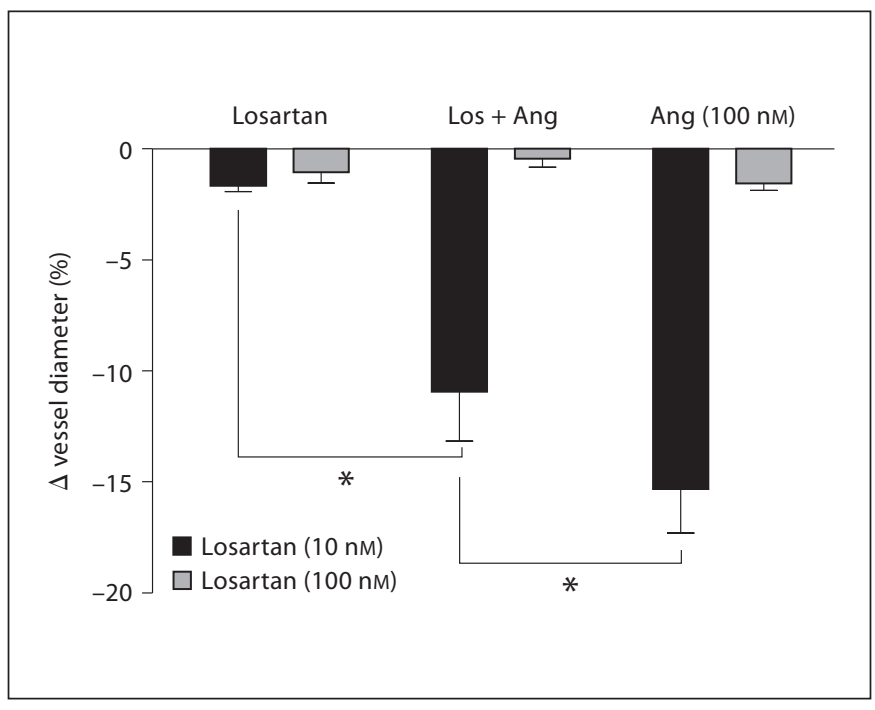

Fig. 7. The $\mathrm{AT}_{1}$ receptor antagonist, losartan, concentration-dependently blocked the Ang-II (100 nM)-evoked constriction of vasa recta at pericyte sites. Losartan alone (10 nM or $100 \mathrm{~nm})$ had no effect on capillary diameter ( $n=8$ and $n=9$, respectively). Losartan (10 nM, black bars) significantly and reversibly attenuated $(\sim 30 \%)$ the maximum Ang-II (100 nM)-evoked vasoconstriction of vasa recta by pericytes $(n=8)$. Losartan $(100 \mathrm{nM}$, grey bars) significantly and irreversibly blocked vasoconstriction of vasa recta by Ang-II $(100 \mathrm{nM}, \mathrm{n}=9)$. Values are mean $\pm \mathrm{SE}$. ${ }^{*} \mathrm{p}<0.05$. significant effect on vasa recta diameter at pericyte sites (fig. 7). No significant change in vasa recta diameter was observed at non-pericyte sites during these experiments (data not shown).

\section{Attenuating Endogenous $\mathrm{NO}$ and $\mathrm{PGE}_{2}$ Release in Kidney Slices}

Indomethacin and L-NAME were applied to kidney slices to attenuate the endogenous release of prostaglandins and NO, respectively. Application of the non-selective cyclooxygenase inhibitor indomethacin $(30 \mu \mathrm{M})$ evoked a significantly greater constriction of vasa recta at pericyte sites $(9.9 \pm 0.5 \%)$ than at non-pericyte sites $(2.1$ $\pm 0.3 \%, \mathrm{n}=13$ slices, $\mathrm{n}=5$ animals, $\mathrm{p}<0.05$; fig. 8 ai) that was consistent with attenuation of production of vasodilator prostaglandins such as $\mathrm{PGE}_{2}$. This effect was reversible following removal of indomethacin. Application of $\mathrm{PGE}_{2}$ to kidney slices evoked dilation of vasa recta that was significantly greater at pericyte sites than at nonpericyte sites $(8.6 \pm 1.6$ and $1.0 \pm 0.8 \%$ respectively, $\mathrm{n}=$ 5 slices, $\mathrm{n}=4$ animals; $\mathrm{p}<0.01$; fig. 8 aii). 
Fig. 8. Attenuating endogenous release of $\mathrm{NO}$ and $\mathrm{PGE}_{2}$ in kidney slices. Superfusion of live kidney slices with the COX inhibitor indomethacin $(30 \mu \mathrm{M})$ evoked a significantly greater constriction of vasa recta at pericyte sites (ai, black bars) compared with non-pericyte sites (ai, grey bars, $n=13)$. Superfusion of $\mathrm{PGE}_{2}(10 \mu \mathrm{M})$ evoked a significantly greater dilation of vasa recta at pericyte sites (aii, black bars) compared with non-pericyte sites (aii, grey bars, $\mathrm{n}=5$ ). Superfusion of the NOS inhibitor L-NAME (1 mM) caused a significantly greater constriction at pericyte sites (b, black bars) than at non-pericyte sites (b, grey bars, $n=7$ ). Washout of L-NAME with PSS caused a significantly greater dilation of vasa recta at pericyte sites (b, black bars) than at non-pericyte sites (b, grey bars, $\mathrm{n}=5$ ). Values are mean $\pm \mathrm{SE}$. ${ }^{*} \mathrm{p}<0.05$.

Fig. 9. Stimulating the release of endogenous vasoactive mediators. Superfusion of kidney slices with tyramine $(1 \mu \mathrm{M})$ evoked a significantly greater constriction at pericyte sites (a, black bars) compared with non-pericyte sites (a, grey bars, $n=7)$. Reducing the osmolarity of the PSS by $5 \%$ caused a significantly greater dilation at pericyte sites (b, black bars) compared with non-pericyte sites (b, grey bars, $\mathrm{n}=5$ ). Values are mean \pm SE. ${ }^{*} \mathrm{p}<0.05$.
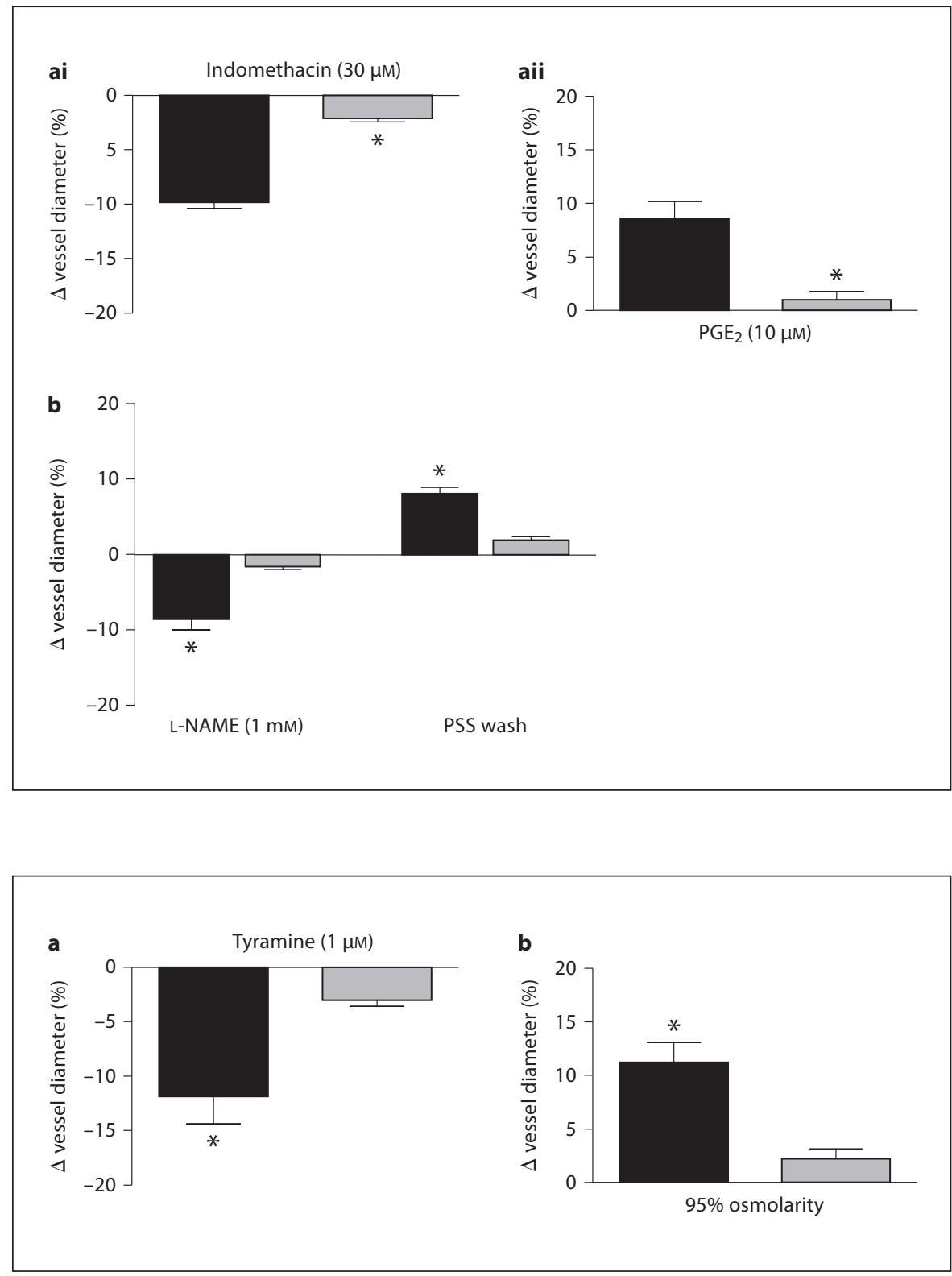

Application of $1 \mathrm{mM}$ L-NAME (to inhibit nitric oxide synthase and NO production) evoked a significantly greater constriction of vasa recta at pericyte sites than at

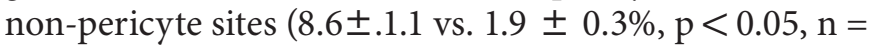
7 slices, $\mathrm{n}=4$ animals; fig. $8 \mathrm{~b}$ ) that reversed after removal of L-NAME. In some experiments following the removal of L-NAME, we observed a dilation of vasa recta at pericyte sites $(8.0 \pm 1.0 \%)$, which was significantly greater than at non-pericyte sites $(1.9 \pm 0.5 \%, \mathrm{n}=5$ slices, $\mathrm{n}=$ 3 animals, $p<0.05$; fig. 8 b). This may be due to a surge in NO production following removal of L-NAME.

\section{Stimulating Endogenous Release of NA and ATP - Demonstrating Neurovascular and Tubulovascular Crosstalk}

Superfusion of live kidney slices with $1 \mu \mathrm{M}$ tyramine (to stimulate NE and ATP production and release from sympathetic nerve terminals) caused a significantly greater vasoconstriction of vasa recta at pericyte sites $(11.9 \pm 2.5 \%)$ compared with non-pericyte sites $(3.0 \pm$ $0.6 \%, \mathrm{n}=7$ slices, $\mathrm{n}=4$ animals; $\mathrm{p}<0.05$; fig. $9 \mathrm{a}$ ). This vasoconstriction was however more moderate than that observed following bath application of $10 \mathrm{nM} \mathrm{NE}(\sim 21 \%)$. 
Tubular epithelial cells and vascular endothelial cells are both known to release vasoactive ATP under conditions of 'stress', such as hypotonicity. Reducing the osmolarity of the PSS by 5\% in the current study caused a significant increase in vasa recta diameter at pericyte sites (11.4 \pm 1.7$)$ compared with non-pericyte sites $(2.2 \pm 0.9$, $\mathrm{n}=5$ slices, $\mathrm{n}=4$ animals; $\mathrm{p}<0.05$; fig. $9 \mathrm{~b}$ ).

\section{Discussion}

The purpose of this study was to develop and explore the potential for a live kidney slice model to investigate vasa recta properties and regulation in situ. Although the vasa recta are not perfused in this preparation, it has the advantage of being intact tissue with both vasa recta and adjacent tubules, and preserved intrarenal innervation; as such is potentially useful for examining the role of vasa recta pericytes in the control of vasa recta capillary diameter, and the effect of exogenously applied and endogenously released vasoactive compounds. Moreover, in the absence of an in vivo method to study vasa recta function in situ, we have shown that the kidney slice model confirms many of the observations already made in isolated vasa recta in vitro, and that the slice model may complement and extend current in vitro techniques.

\section{Tissue Viability}

Kidney slices are viable and have an $80 \%$ ratio of live to dead cells using Hoechst and PI. This is similar to the ratio reported previously for healthy rat kidneys [23], and a value that was also obtained in the established rat brain slice preparation [7]. Furthermore, the uptake of calcein into both vascular and tubular cells in the renal medulla is not dissimilar to that in the renal cortex of transverse cut rat kidney slices shown by Hall et al. [24]. These findings indicate that kidney slice tissue is viable for physiological experiments.

\section{Characteristics of in situ Vasa Recta and Their Pericytes}

Using anti-NG2 antibody to identify pericytes [25] in the renal medulla and to investigate the characteristics of in situ pericytes on vasa recta capillaries (identified with $\mathrm{IB}_{4}$ ) in live kidney slices, we found a significantly higher density of pericytes in the outer medulla compared with the inner medulla - similar to previous reports in sections of tissue dissected from the inner and outer medulla of rat kidneys [26]. We also found a wide range of $1^{\circ}$ process lengths $(2-18 \mu \mathrm{m})$ extending from the cell body and running in parallel along, and wrapping around, the vasa recta. Given that the average distance between pericyte cell bodies is $\sim 16 \mu \mathrm{m}$, and the average process length is $\sim 8 \mu \mathrm{m}$, there are unlikely to be many regions along the vasa recta that are not covered with pericyte processes, which probably account for the small changes in vasa recta diameter $(<7 \%)$ at non-pericyte sites when Ang-II and $\mathrm{NE}$ were applied (fig. $4 \mathrm{c}$ and 5 ai, respectively); endothelial cells are unlikely to contract and cause changes in vessel diameter.

Interestingly, the density of pericytes on vasa recta is greater than that reported for many other tissues (for example in the mouse, CNS pericytes reside mainly at capillary branch points and have a distance of $\sim 50 \mu \mathrm{m}$ between cell bodies [27]). The fluorescently conjugated $\mathrm{IB}_{4}$ used to label vasa recta was not able to distinguish between AVR and DVR in our kidney slices, and we cannot comment on AVR/DVR vessel diameter or pericyte density on DVR versus AVR.

In this study, sympathetic nerves were identified in close proximity to outer medullary pericytes. Since sympathetic nerves release NE, it is likely that these are an endogenous source of vasoactive NE in the medulla. When applied exogenously to kidney slices, $10 \mathrm{nM} \mathrm{NE}$ elicited vasoconstriction of vasa recta specifically at pericyte sites (see Results and fig. 5ai-iv). The application of tyramine also evoked pericyte-mediated vasoconstriction of in situ vasa recta. Given the close proximity of sympathetic nerves to vasa recta pericytes, we propose that tyramine stimulates local release of NE and ATP from sympathetic varicosities, and that this acts at apposite pericytes to cause pericyte contraction and constriction of vasa recta at that site. The constriction observed in tyramine experiments was however more moderate when compared with the pericyte-mediated constriction of vasa recta evoked by bath application of $10 \mathrm{nM}$ NE. This is not perhaps surprising given that local concentration of NE has previously been determined for both the iris and vas deferens and is in the picomolar range, and thus significantly $<10 \mathrm{nM}$ [28].

Vasa recta capillaries in our study measured 7-10 $\mu \mathrm{m}$ in diameter, which is smaller than others have reported. Holliger et al. [29] reported a vessel diameter for both AVR $(20 \mu \mathrm{m})$ and DVR $(15 \mu \mathrm{m})$, when investigating vasa recta in the exposed papilla of young rats, and more recently vasa recta used in an in vitro microperfusion study were reported to have diameters of $13-15 \mu \mathrm{m}[9,30]$. The mean resting vessel diameter of non-perfused isolated DVR (pericyte vs. non-pericyte sites not defined in this early publication) is reported to be $\sim 11.5 \pm 1 \mu \mathrm{m}$, which 
increases to $15.5 \mu \mathrm{m}$ when DVR are perfused with a perfusion pressure up to $75 \mathrm{~mm} \mathrm{Hg}$. When perfused at a more physiological value of $25 \mathrm{~mm} \mathrm{Hg}$, mean isolated perfused DVR diameter is $\sim 14.5 \mu \mathrm{m}$ [30], which is much closer to the values we determined for the outer vessel diameter $(12.6 \pm 0.5 \mu \mathrm{m})$ in our preparation. However, the measured diameters of microvessels in the present study are for the inner diameter and not the outer (which is usually the value given for isolated perfused DVR). The mean diameter of vasa recta at pericyte and non-pericyte sites was calculated to be $\sim 7.5$ and $\sim 9.5 \mu \mathrm{m}$, respectively. Given that endothelial cells are generally considered to be $1-2$ $\mu \mathrm{m}$ thick, this could increase vessel diameter to 9.5-11.5 and $11.5-13.5 \mu \mathrm{m}$ at pericyte and non-pericyte sites, respectively.

\section{Functional Experiments on Pericytes}

Agonist-evoked constriction of individual vasa recta in situ by pericytes can be measured in real time (see online suppl. video 1 as an example). Moreover, we found that endogenous signalling mechanisms are functioning in this kidney slice model, and that endogenous agents (NO and $\mathrm{PGE}_{2}, \mathrm{NE}$ and $\mathrm{ATP}$ ) are acting via contractile pericytes to regulate vasa recta diameter, and changes in vessel diameter were significantly greater at pericyte sites compared with non-pericyte sites in all our experiments. Agonist-evoked changes in vasa recta diameter were observed at a small proportion of pericyte sites in each vessel, and in total occurred in approximately $51 \%$ of all vessels examined. The lack of response of some pericytes here is similar to findings on isolated and in situ retinal vessels. A P2X7 agonist contracted $37 \%$ of isolated retinal pericytes and capillary constriction occurred in only $12 \%$ of the total [31]; a muscarininc agonist contracted just $10 \%$ of retinal pericytes [32]. In whole mount retina, UTP and ATP constricted 30 and $25 \%$ of total pericytes, respectively [7]. In cerebellar slices, NA constricted $50 \%$ of pericytes, and only $20 \%$ of pericytes responded to glutamate [7]. The ranging success rate $(35-83 \%)$ we observed in kidney tissue is in line with, or greater than, that observed in CNS experiments $[7,31,32]$ (which is presumably in part due to the relative potency of the respective agonists used and whether they are acting at direct receptors, or stimulating endogenous release of other vasoactive compounds), and this finding correlates well with our observation that pericyte density is greater along vasa recta capillaries than along CNS capillaries. We suggest that if all pericytes were to constrict uniformly as a syncytium, the resulting vasoconstriction and reduction in medullary blood flow would be quite profound and detrimental to the already borderline hypoxic tissue. We believe that pericytes act to regulate vasa recta diameter in a finite way, offering regional redistribution of blood flow and fine-tuning of blood flow, as opposed to causing complete cessation of blood flow. The fact that not all pericytes appear to constrict, both in our preparation and in other tissue beds investigated to date, does seem to support this concept.

Agonist-evoked changes in vessel diameter were reversible and vessels returned to $\sim 97 \%$ of their original resting diameter following removal of all agonists, except for ET-1, where vasa recta diameter only returned to 76.5 $\pm 5.9 \%$. Our findings agree with previous reports that Ang-II, NE and ET-1 significantly reduce blood flow in the medulla [1]. In our experiments we considered an agent more likely to reduce medullary blood flow when vasa recta diameter (normally $\sim 10 \mu \mathrm{m}$ ) is decreased enough to impede the passage of red blood cells (RBCs; diameter of 7-8 $\mu \mathrm{m})$, for example Ang-II (100 nM) caused a $29 \%$ decrease in vasa recta diameter, which could significantly impede the flow of RBCs.

Ang-II-evoked vasoconstriction was unusual in that vessels started to dilate (toward their resting diameter) before the removal of Ang-II. This indicates possible desensitization of $\mathrm{AT}_{1}$ receptors, perhaps due to release of vasodilatory $\mathrm{NO}$. $\mathrm{AT}_{1}$ receptor-stimulated release of $\mathrm{NO}$ has been reported in mouse afferent arterioles [33]; this effect has also been observed in isolated rat DVR in which chronic infusion of Ang-II enhanced basal production of NO [34]. Since Ang-II is endogenous to the kidney, it is likely that local vasodilatory mechanisms exist to counteract excessive Ang-II-induced vasoconstriction. Indeed, we have shown that (unperfused) vasa recta in kidney slices are capable of producing NO. Application of L-NAME, an inhibitor of NOS and NO production, caused vessels to constrict, suggesting that $\mathrm{NO}$ is released tonically in kidney slices and that it may determine resting vessel diameter. In experiments where kidney slices were exposed to Ang-II and the NO donor SNAP, SNAP attenuated the Ang-II-evoked constriction of vasa recta at pericyte sites when the Ang-II concentration was low $(10 \mathrm{nM})$, but not at a higher concentration $(100 \mathrm{nM})$.

Another possible trigger for local $\mathrm{NO}$ release in the slice preparation are RBCs present in the lumen of 50\% of all vasa recta exposed to Ang-II (fig. 4ai-iii). Since $\mathrm{RBCs}$ are known to release ATP in response to deformation caused by vessel constriction [35], and that ATP can then lead to release of $\mathrm{NO}$ from the vascular endothelium [36], it is possible that pericyte-mediated constriction of 
vasa recta containing RBCs could result in ATP-mediated release of vasodilatory $\mathrm{NO}$. Of the vasa recta containing RBCs, $87.5 \%$ recovered prior to washout of Ang-II compared with vasa recta without RBCs, in which only $50 \%$ recovered prior to Ang-II washout. The $\mathrm{AT}_{1}$ receptor antagonist losartan, at $100 \mathrm{nM}$, fully and irreversibly blocked Ang-II-evoked vasoconstriction of vasa recta at pericytes, whereas $10 \mathrm{~nm}$ losartan only partially blocked this effect. Thus, our findings are consistent with data collected in similar experiments on isolated DVR [37]. Inhibition of Ang-II-evoked constriction by losartan confirms $\mathrm{AT}_{1}$ receptors are present on the surface of vasa recta pericytes and probably mediate the Ang-II-evoked constriction of vasa recta by contracting pericytes.

In addition to attenuating endogenous production of $\mathrm{NO}$, we have also shown that application of indomethacin caused vasa recta to constrict (see Results and fig. 8ai). Indomethacin is a selective COX-1 inhibitor and inhibits the synthesis of vasodilatory prostaglandins, including $\mathrm{PGE}_{2}$. We have demonstrated here that $\mathrm{PGE}_{2}$ evoked vasodilation of vasa recta at pericyte sites, this in combination with the indomethacin-evoked vasoconstriction suggests that the pericyte-mediated constriction observed in the presence of indomethacin is in part due to inhibition of vasodilatory $\mathrm{PGE}_{2}$.

In order to address the question of whether the live kidney slice model is suitable for investigating tubulovascular crosstalk, we sought to initiate ATP release from tubular epithelial cells by applying a hypotonic PSS solution to live kidney slices. Cultured tubular epithelial cells have previously been shown to release ATP under conditions of stress, such as pressure [38], and hypotonicity [39]. In the current study, we observed pericyte-mediated vasodilation in response to application of a hypotonic PSS indicative of ATP-mediated vasodilation. In cerebral vascular beds, ATP has been shown to cause both vasoconstriction and vasodilation [40,41]. Moreover, in the live kidney slice model, we have previously demonstrated that high concentrations of ATP $(100 \mu \mathrm{M})$ caused pericyte-mediated vasoconstriction [20]. In experiments where slices were exposed to inhibitors of the ATP-gated P2 receptors (suramin), we observed constriction of vasa recta at pericyte sites indicating low concentrations of ATP, such as that released locally, were tonically acting to dilate vasa recta [20]. Data presented here show that endogenous ATP release does indeed act to regulate vasa recta diameter; however, since we cannot demonstrate that the source of ATP release is solely tubular in its origin, findings presented here are perhaps the first step towards investigating tubulovascular crosstalk mechanisms in situ.

Kidney Slice Model to Study Vasa Recta Pericyte Function
Ang-II-Evoked Changes in Renal Blood Flow: in situ vs. in vitro vs. in vivo

To explore the value of this model as an in situ technique to investigate how medullary blood flow may be controlled locally, we compared changes in flow evoked by Ang-II in our in situ slice preparation with previously published in vitro isolated DVR experiments [9], and in vivo studies performed in our laboratory using intrarenal laser Doppler flowmetry (LDF) in rats [unpubl. data, see 42 for method]. Here we utilize Poiseuille's law to determine approximate changes in blood flow in response to Ang-II. Values presented are an approximation and determined by extrapolating data from measured changes in vessel diameter, therefore values are a simplification of the likely in vivo blood flow dynamic. Comparing concentration-matched data (10 nM Ang-II), we calculated an approximate $55 \%$ decrease in vasa recta blood flow in our slice experiments, which is less than that calculated for corresponding in vitro isolated DVR experiments (92\%). Interestingly, in in vivo LDF experiments following the systemic infusion of Ang-II ( $3 \mu \mathrm{g} / \mathrm{min} / \mathrm{kg}$; which equates to $250 \mu \mathrm{l}$ of $\sim 20 \mu \mathrm{M}$ Ang-II over $5 \mathrm{~min}$; the maximum concentration that can be safely infused [unpubl. finding]), we observed only a $20.2 \pm 5.4 \%(n=9)$ change in medullary blood flow [unpubl. data]. This in vivo value is in keeping with other in vivo experiments reported in rats in which a $28 \%$ change in medullary blood flow was measured by LDF following Ang-II infusion [43]. Responses calculated for both the in situ slice model and in vitro DVR model are higher than the measured in vivo response, which is not surprising given the complex physiological regulation of blood in vivo; however, it is interesting that the value obtained using the slice preparation is intermediate between the in vitro and in vivo values, perhaps reflecting its relatively intact nature, though still lacking perfusion, as well as the normal osmotic and oxygen gradients present in vivo.

\section{Conclusion}

Many of the limitations of the kidney slice model have already been alluded to. Ideally, an improved model would include vasa recta luminal perfusion, as well as simulation of the osmotic and oxygen gradients found in vivo, which are both technically challenging. However, despite these limitations, the current model may still have a useful place alongside the techniques currently available to study medullary blood flow, and may even be complementary.

Nephron Physiol 2012;120:p17-p31 p29 
We have shown that the kidney slice model is not a technically demanding preparation to set up, and that it can be used to demonstrate pharmacological effects on vasa recta pericytes, which are likely to have physiological relevance, and are not qualitatively dissimilar to what has been reported in vitro. However, what we see as the potential advantage of this technique is that is can be used to explore the structure-function relationship between the vasa recta and adjacent renal tubules, and the role of local innervation, not only in normal healthy renal tissue, but also in slices taken from models of acute kidney injury to investigate its pathophysiology.

\section{Acknowledgements}

We are grateful to Prof. Michael Duchen and Dr. Andrew M. Hall for their assistance and use of the 2-photon, Zeiss 510 NLO Axiovert microscope and Prof. Mervyn Singer (University College London) for the use of the in vivo Laser Doppler equipment. This work was supported by The UK Medical Research Council and The Royal Veterinary College Internal Grant Scheme to C.M.P.-W. and The Wellcome Trust S.S.P.W. The 2-photon, Zeiss 510 NLO Axiovert microscope at UCL is funded by a SRIF Grant.

\section{References}

$>1$ Pallone TL, Zhang Z, Rhinehart K: Physiology of the renal medullary microcirculation. Am J Physiol Renal Physiol 2003;284:F253F266.

$\checkmark 2$ Agmon Y, Dinour D, Brezis M: Disparate effects of adenosine $\mathrm{A}_{1}$ - and $\mathrm{A}_{2}$-receptor agonists on intrarenal blood flow. Am J Physiol 1993;265:F802-F806.

$>3$ Mattson DL, Roman RJ, Cowley AW Jr: Role of nitric oxide in renal papillary blood flow and sodium excretion. Hypertension 1992; 19:766-769.

$\checkmark 4$ Mattson DL, Lu S, Roman RJ, Cowley AW Jr: Relationship between renal perfusion pressure and blood flow in different regions of the kidney. Am J Physiol 1993;264:R578R583.

5 Roman RJ: Pressure-diuresis in volume-expanded rats. Tubular reabsorption in superficial and deep nephrons. Hypertension 1988; 12:177-183.

$>6$ Cupples WA, Marsh DJ: Autoregulation of blood flow in renal medulla of the rat: no role for angiotensin II. Can J Physiol Pharmacol 1988;66:833-836.

7 Peppiatt CM, Howarth C, Mobbs P, Attwell D: Bidirectional control of CNS capillary diameter by pericytes. Nature 2006;443:700704.

$>8$ Pallone TL, Robertson CR, Jamison RL: Renal medullary microcirculation. Physiol Rev 1990;70:885-920.

$\checkmark 9$ Pallone TL: Vasoconstriction of outer medullary vasa recta by angiotensin II is modulated by prostaglandin $\mathrm{E}_{2}$. Am J Physiol 1994; 266:F850-F857.

-10 Pallone TL, Silldorff EP, Cheung JY: Response of isolated rat descending vasa recta to bradykinin. Am J Physiol 1998;274:H752H759.

11 Rhinehart KL, Pallone TL: Nitric oxide generation by isolated descending vasa recta. Am J Physiol Heart Circ Physiol 2001; 281:H316-H324.
12 Silldorff EP, Yang S, Pallone TL: Prostaglan$\operatorname{din} \mathrm{E}_{2}$ abrogates endothelin-induced vasoconstriction in renal outer medullary descending vasa recta of the rat. J Clin Invest 1995;95:2734-2740.

13 Silldorff EP, Kreisberg MS, Pallone TL: Adenosine modulates vasomotor tone in outer medullary descending vasa recta of the rat. J Clin Invest 1996;98:18-23.

14 Silldorff EP, Pallone TL: Adenosine signaling in outer medullary descending vasa recta. Am J Physiol Regul Integr Comp Physiol 2001;280:R854-R861.

15 Thiel G, de Rougemont D, Kriz W, Mason J, Torhorst J, Wolgast M: The role of reduced medullary perfusion in the genesis of acute ischemic renal failure. Summary of a roundtable discussion. Nephron 1982;31:321-323.

16 MacPhee PJ: Fluid uptake by the renal medullary vasa recta: an estimate based on a quantitative analysis of the distribution of fenestrae in the vasa recta of young SpragueDawley rats. Exp Physiol 1998;83:23-34.

17 Pallone TL, Silldorff EP: Pericyte regulation of renal medullary blood flow. Exp Nephrol 2001;9:165-170.

18 Bratosin D, Mitrofan L, Palii C, Estaquier J, Montreuil J: Novel fluorescence assay using calcein-AM for the determination of human erythrocyte viability and aging. Cytometry A 2005;66:78-84.

19 Shepro D, Morel NM: Pericyte physiology. FASEB J 1993; 7:1031-1038.

20 Crawford C, Kennedy-Lydon TM, Callaghan H, Sprott C, Simmons RL, Sawbridge L, Syme HM, Unwin RJ, Wildman SS, PeppiattWildman CM: Extracellular nucleotides affect pericyte-mediated regulation of rat in situ vasa recta diameter. Acta Physiol (Oxf) 2011;202:241-251.
21 Landis EM: Factors controlling the movement of fluid through the human capillary wall. Yale J Biol Med 1933;5:201-225.

22 Hamilton NB, Attwell D, Hall CN: Pericytemediated regulation of capillary diameter: a component of neurovascular coupling in health and disease. Front Neuroenergetics 2010;2:pii 5.

23 Dunn KW, Sandoval RM, Kelly KJ, Dagher PC, Tanner GA, Atkinson SJ, Bacallao RL, Molitoris BA: Functional studies of the kidney of living animals using multicolor twophoton microscopy. Am J Physiol Cell Physiol 2002;283:C905-C916.

24 Hall AM, Unwin RJ, Parker N, Duchen MR: Multiphoton imaging reveals differences in mitochondrial function between nephron segments. J Am Soc Nephrol 2009;20:1293302.

25 Hughes S, Chan-Ling T: Characterization of smooth muscle cell and pericyte differentiation in the rat retina in vivo. Invest Ophthalmol Vis Sci 2004;45:2795-2806.

26 Park F, Mattson DL, Roberts LA, Cowley AW Jr: Evidence for the presence of smooth muscle $\alpha$-actin within pericytes of the renal medulla. Am J Physiol 1997;273:R1742-R1748.

27 Armulik A, Genove G, Mae M, Nisancioglu $\mathrm{MH}$, Wallgard E, Niaudet C, He L, Norlin J, Lindblom P, Strittmatter K, Johansson BR, Betsholtz C: Pericytes regulate the bloodbrain barrier. Nature 2010;468:557-561.

28 Dahlstrom A, Haggendal J, Hokfelt T: The noradrenaline content of the varicosities of sympathetic adrenergic nerve terminals in the rat. Acta Physiol Scand 1966;67:289-294.

29 Holliger C, Lemley KV, Schmitt SL, Thomas FC, Robertson CR, Jamison RL: Direct determination of vasa recta blood flow in the rat renal papilla. Circ Res 1983;53:401-413.

30 Zhang Z, Pallone TL: Response of descending vasa recta to luminal pressure. Am J Physiol Renal Physiol 2004;287:F535-F542. 
31 Kawamura H, Sugiyama T, Wu DM, Kobayashi M, Yamanishi S, Katsumura K, Puro DG: ATP: a vasoactive signal in the pericytecontaining microvasculature of the rat retina. J Physiol 2003;551:787-799.

32 Wu DM, Kawamura H, Sakagami K, Kobayashi M, Puro DG: Cholinergic regulation of pericyte-containing retinal microvessels. Am J Physiol Heart Circ Physiol 2003; 284:H2083-H2090.

-33 Patzak A, Lai EY, Mrowka R, Steege A, Persson $\mathrm{PB}$, Persson AE: AT1 receptors mediate angiotensin II-induced release of nitric oxide in afferent arterioles. Kidney Int 2004;66: 1949-1958.

>34 Zhang Z, Rhinehart K, Solis G, Pittner J, LeeKwon W, Welch WJ, Wilcox CS, Pallone TL: Chronic ANG II infusion increases NO generation by rat descending vasa recta. Am J Physiol Heart Circ Physiol 2005;288:H29H36.
5 Sprague RS, Ellsworth ML, Stephenson AH, Lonigro AJ: ATP: the red blood cell link to $\mathrm{NO}$ and local control of the pulmonary circulation. Am J Physiol 1996;271:H2717H2722.

36 Bogle RG, Coade SB, Moncada S, Pearson JD, Mann GE: Bradykinin and ATP stimulate Larginine uptake and nitric oxide release in vascular endothelial cells. Biochem Biophys Res Commun 1991;180:926-932.

37 Rhinehart K, Handelsman CA, Silldorff EP, and Pallone TL: ANG II AT2 receptor modulates AT1 receptor-mediated descending vasa recta endothelial $\mathrm{Ca}^{2+}$ signaling. Am J Physiol Heart Circ Physiol 2003;284:H779H789.

38 Praetorius HA, Frokiaer J, Leipziger J: Transepithelial pressure pulses induce nucleotide release in polarized MDCK cells. Am J Physiol Renal Physiol 2005;288:F133-F141.

39 Jans D, Srinivas SP, Waelkens E, Segal A, Lariviere E, Simaels J, Van Driessche W: Hypotonic treatment evokes biphasic ATP release across the basolateral membrane of cultured renal epithelia (A6). J Physiol 2002; 545:543-555.
40 Horiuchi T, Dietrich HH, Tsugane S, Dacey RG Jr: Analysis of purine- and pyrimidineinduced vascular responses in the isolated rat cerebral arteriole. Am J Physiol Heart Circ Physiol 2001;280:H767-H776.

41 Dietrich HH, Kajita Y, Dacey RG Jr: Local and conducted vasomotor responses in isolated rat cerebral arterioles. Am J Physiol 1996;271:H1109-H1116.

42 Whitehouse T, Stotz M, Taylor V, Stidwill R, Singer M: Tissue oxygen and hemodynamics in renal medulla, cortex, and corticomedullary junction during hemorrhage-reperfusion. Am J Physiol Renal Physiol 2006; 291:F647-F653.

43 O'Connor PM, Kett MM, Anderson WP, Evans RG: Renal medullary tissue oxygenation is dependent on both cortical and medullary blood flow. Am J Physiol Renal Physiol 2006; 290:F688-F694. 